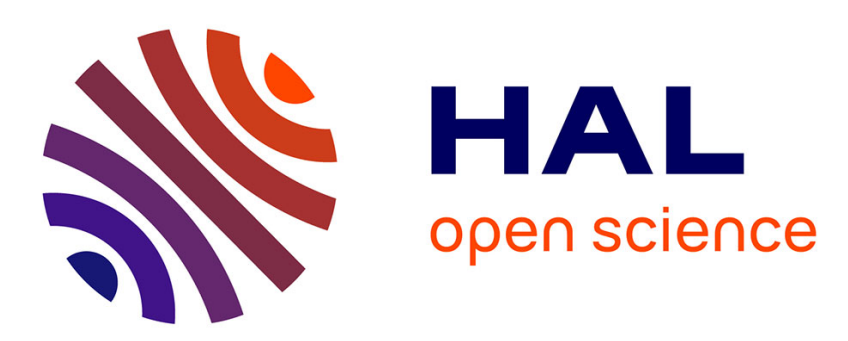

\title{
Simplified modeling of the convection and radiation heat transfers during the infrared heating of PET sheets and preforms Nomenclature
}

Yun Mei Luo, Luc Chevalier, Françoise Utheza, Xavier Nicolas

\section{- To cite this version:}

Yun Mei Luo, Luc Chevalier, Françoise Utheza, Xavier Nicolas. Simplified modeling of the convection and radiation heat transfers during the infrared heating of PET sheets and preforms Nomenclature. International Polymer Processing, 2015, 30 (5), pp.554-565. 10.3139/217.3092 . hal-01238882

\section{HAL Id: hal-01238882 \\ https://hal.science/hal-01238882}

Submitted on 8 Dec 2015

HAL is a multi-disciplinary open access archive for the deposit and dissemination of scientific research documents, whether they are published or not. The documents may come from teaching and research institutions in France or abroad, or from public or private research centers.
L'archive ouverte pluridisciplinaire HAL, est destinée au dépôt et à la diffusion de documents scientifiques de niveau recherche, publiés ou non, émanant des établissements d'enseignement et de recherche français ou étrangers, des laboratoires publics ou privés. 


\title{
Simplified modeling of the convection and radiation heat transfers during the infrared heating of PET sheets and preforms
}

\author{
Yun Mei Luo ${ }^{*}$, Luc Chevalier, Françoise Utheza, Xavier Nicolas \\ *corresponding author: yunmei.luo@univ-paris-est.fr \\ Université Paris-Est, Laboratoire Modélisation et Simulation Multi Echelle, \\ MSME UMR 8208 CNRS, \\ Marne-la-Vallée, France
}

\section{Abstract}

Initial heating conditions and temperature effects have important influence during the ISBM process of PET preforms. The numerical simulation of infrared (IR) heating taking into account the air convection is very time-consuming even for $2 \mathrm{D}$ modelling. This work proposes a simplified approach of the coupled heat transfers in the ISBM process based on the results of a complete air convection and IR heating simulation of PET sheet using ANSYS/Fluent. First, the simplified approach is validated by comparing the experimental temperature distribution of a PET sheet obtained from an IR camera with the numerical results of the simulation. Second, we focus on the PET preform heated by IR lamps. This problem cannot be modelled in 2D and the complete 3D approach is out of calculation possibilities actually. In our approach, the IR heating flux coming from IR lamps is calculated using radiative laws adapted to the test geometry. Finally, the simplified approach used on the 2D plane sheet case to model the air convection is applied to the heat transfer between the preform and ambient air using a simpler model in Comsol where only the preform is meshed. The temperature distribution on the outer surface of the preform is compared to the thermal imaging for validation.

Keywords: Thermal properties, radiation, simulations 


\begin{tabular}{|c|c|}
\hline \multicolumn{2}{|c|}{ Nomenclature } \\
\hline$C_{p}$ & specific heat capacity \\
\hline$h_{f}$ & convection heat transfer coefficient on the face in front of the lamps \\
\hline$h_{r}$ & convection heat transfer coefficient on the rear face of the sheet \\
\hline$k$ & material conductivity \\
\hline$k_{\lambda}$ & spectral absorption coefficient of PET \\
\hline$N u$ & Nusselt number \\
\hline $\operatorname{Pr}$ & Prandtl number \\
\hline $\overrightarrow{q_{r}}$ & internal radiative heat flux \\
\hline$T_{g}$ & glass transition temperature \\
\hline $\begin{array}{l}T_{\infty} \\
\text { Greek }\end{array}$ & surrounding bulk temperature $\left(20^{\circ} \mathrm{C}\right)$ \\
\hline$\alpha$ & factor that fits the steep jump of the $\rho C_{p}(\mathrm{~T})$ function \\
\hline$\Delta \rho C_{p}$ & $\begin{array}{l}\text { constant related to the amplitude of the } \rho C_{p} \text { increase when passing from the } \\
\text { glassy state to the rubber state }\end{array}$ \\
\hline$\phi_{\lambda 0}$ & incident radiation \\
\hline$\rho$ & density \\
\hline $\begin{array}{l}\rho C_{p 1} \\
\text { Subscr }\end{array}$ & value corresponding to the glassy state of the material \\
\hline$a$ & refer to air \\
\hline$w$ & refer to a quantity measured at wall surface \\
\hline
\end{tabular}




\section{Introduction}

The effects of temperature and heating conditions have a fundamental importance during the Injection Stretch Blowing Molding (ISBM) process of PET preforms. The mechanical properties of PET are related to the microstructural morphology of the material and strongly depend on the process temperature as well as on the strain rates. There is a great industrial interest in predicting the temperature distribution at the beginning and during the ISBM process: it is a scientific problem that has been addressed by numerous authors during the 15 last years.

Regarding the numerical approach, Venkateswaran et al. (1998) were among the first to model the temperature profile through the thickness of the preform by solving the energy equation with radiation as the source term and they provided an experimental validation by measuring the surface temperatures using infrared thermocouples. The conducted simulation was $1 \mathrm{D}$, on several positions of the preform, and did not take into account the conduction in the direction normal to the thickness. Yousefi et al. (2001) used a finite element approach for the modeling of the heat exchanges between the preform and the infrared oven. Taking into account the rotation of the preform, the convection and the hypothesis of a gray body for PET, the temperature profile on the heated preform was calculated. However, the temperature gradient in the thickness of the preform was not considered. Later, Huang et al. (2005) modeled the infrared (IR) heating of the preform by calculating a radiative flux term received by the preform surface and then diffused into the material by conduction. The model was validated through comparisons with temperature measurements by thermocouples in the thickness of the preform. Following Monteix (2001), Champin (2007) and Bordival (2009) used the thermal properties identified in (Monteix 2001) to model the IR heating in the case of a 3D preform. A radiation source term was implemented in the heat equation. This volume source term was calculated by the method of ray tracing, coupled with a spectral absorption law of Beer Lambert. This approach was continued by Cosson et al. (2011) in order to 
develop the ray tracing method for the computation of the radiative source term in IR heating. This method was shown to be efficient to predict the temperature distribution of the preform. More recently, Erchiqui et al. (2009) used a simplified approach and the finite element method to analyze the temperature evolution in a semi-transparent thin membrane of the amorphous PET, subjected to a radiative source. All these works focus on the IR heating modeling and do not consider the natural air convection around the PET samples.

Regarding the experimental approach, studies on the PET sheet, a more simple geometry than a preform, were carried out at the first time in Lebaudy et al. (1995), Schmidt et al. (2003) and Monteix et al. (2001). Their purpose was to characterize the thermal parameters of the infrared oven and the interaction between the emitter and the PET sheet. The experimental results available in Lebaudy et al. (1995), Schmidt et al. (2003) and Monteix et al. (2001) were also used to validate numerical simulations. Recently, Salomeia et al. (2013) and Menary (2012) did the first temperature measurements of the air blown inside the bottle. They showed that the temperature of the air increases as soon as the preform is introduced in the mold, before the beginning of the preblow. However, only one thermocouple junction was mounted in the metallic stretch rod by using a silicon sealant. Therefore, there is only one curve presenting the variation of the temperature of the air blown in the hot preform. This work provides important data for the thermal boundary conditions of the ISBM simulations. Currently, they are working on measuring the internal and external surface temperatures of a preform since the industry has no means to accurately measure them. In our previous papers (Luo et al. 2012, 2013, 2014) we have presented a contribution on the thermal aspects of the ISBM process, in which the procedure for the identification of the thermal properties is performed on PET sheets from IR heating tests. From the measurement of the temperature field during the IR heating of the PET sheet, it has been shown that the temperature at the bottom of the PET sheet is lower than anywhere else in the surface (Luo et 
al. 2014). The surrounding air, heated by the PET sheet temperature, becomes lighter and rises along the sheet carrying cold air from the bottom region: this is the effect of the natural or free convection of air. The convective heat transfer, resulting from the temperature difference between the sheet and the ambient air, plays an important role in the temperature distribution in the sheet that cannot be accurately taken into account using a global convection heat transfer coefficient.

The main goal of this paper is to provide accurate thermal boundary conditions to perform a 3D thermal finite element simulation of the infrared heating. This means to manage the calculation of the infrared flux and to provide a convection heat transfer able to reproduce the natural air convection effect. This goal is relevant in an industrial context where $2 \mathrm{D}$ or $3 \mathrm{D}$ complete calculations including the PET sample and the convection of the surrounding air is very time consuming.

The next Section II presents the procedure used to identify the convection heat transfer evolution along the plane PET sample from a complete 2D simulation carried out using the Ansys/Fluent software. Furthermore it shows how the result of this simulation (the knowledge of the local heat transfer coefficient) can be coupled with the IR flux calculation to manage a 3D modelling of the IR heating of the plane PET sample alone (without the ambient air).

Section III uses the simplified free convection model of Section II and also an IR flux adapted to the cylindrical and semi spherical geometry of a PET preform to simulate the IR heating of this preform. This numerical simulation takes into account the rotation of the preform in front of the lamps. The results of this simulation, the time evolution and the space distribution of the PET preform temperature, are compared to experimental measurements conducted on a rotating preform. 


\section{Identification of the thermal boundary conditions for the infrared heating simulation of a PET sheet}

In this section a full 2D simulation of the IR heating of a PET sheet inside the open enclosure of the heating apparatus is conducted with the Ansys/Fluent software that solves the mass, momentum and energy equations, coupled with the radiative transfer equation, by a finite volume method. The thermal behavior of both the ambient air and PET sample are modeled and the velocity, pressure and temperature fields are calculated on the whole domain. These results enable to compute the convective and radiative fluxes on each point of the plane wall of the PET sheet and the difference between the local wall temperature and the mean temperature of the surrounding air, to determine the convection heat transfer coefficient along the sheet boundary. From this result, coupled with the calculation of the IR flux coming from the lamps, a 3D finite element simulation is conducted with the Comsol Multiphysics software for the PET sheet alone, and the temperature distribution on the sheet surface is compared to experimental results.

\section{II.1 Complete 2D model of IR heating and natural air convection}

The IR heating apparatus was modeled in 2D for a first analysis of the influence of the air free convection. All the material and thermal properties of PET are given from previous experiments (Luo et al. 2012, 2013) and summarized in Table 1. The volume of the apparatus is represented by a rectangle, as shown in Fig. 1. The small rectangle in the center of Fig. 1 represents the $3 \mathrm{~mm}$ thick and $12.5 \mathrm{~cm}$ high PET sheet. The 8 IR lamps have a $4 \mathrm{~mm}$ diameter. In order to simplify the study in Ansys/Fluent, they were considered as straight segments of $4 \mathrm{~mm}$ high. They are separated by seven $15 \mathrm{~mm}$ long adiabatic interstices. On these 8 segments, the IR flux is imposed to $7900 \mathrm{~W} / \mathrm{m}^{2}$. This intensity is obtained from the electric consumption of the heating apparatus divided by the total surface of the lamps. 
The walls of the enclosure (left, bottom and top boundaries) that contains the lamps and the PET sheet are assumed to be adiabatic and radiate through the atmosphere to the open boundaries (right boundaries). The calculation takes into account the radiation by solving the radiative transfer equation in air and PET. The PET is assumed to be a semi-transparent medium: the value of its emissivity is 0.93 (Bordival 2009) and the absorption coefficient is $3.10^{4} \mathrm{~m}^{-1}$.

Considering the velocity problem, a no-slip condition is applied at walls, on the whole left, bottom and top boundaries. On the open boundary (on the right), which is the opening that allows us to follow the temperature with the thermal camera in the experiments, the relative static pressure $P S=0$ is imposed ( $P S$ is relative to $\left.P_{a t m}\right)$. The velocity is equal to zero and the air and PET temperatures are equal to $293 \mathrm{~K}$ at the initial condition. During the simulation, the temperature of the air entering in the computational domain is also $293 \mathrm{~K}$.

The continuity, Navier-Stokes and energy equations are solved using the second order Quick discretization scheme to calculate the velocity, pressure and temperature fields. The whole non-linear system of equations is solved by a segregated method and a time implicit scheme (PISO algorithm) in the software Ansys/Fluent. Since the computational domain is open, wide and its geometry is quite complicated, a multi-block domain with a hybrid mesh was built to be able to appropriately refine the mesh in the boundary layers near the heating lamps and the PET sheet. The mesh is structured at the boundary layers and unstructured in other volumes to limit the total number of elements. Over 250,000 cells are generated as following:

- Structured fine mesh where boundary layers develop: along the lamps, on the both sides of the PET sheet and along the top wall;

- Structured mesh between the lamps and the sheet because an upward flow of chimney type develops; 
- Unstructured mesh on the region below and on the right of the sheet, in order to limit the number of computation points.

The radiative flux is calculated by the method of discrete ordinates which transforms the integro-differential radiative transfer equation into an algebraic system of equations. The radiative transfer equation in the direction $\vec{s}$ for the spectral intensity, $I_{\lambda}$, which allows the modeling of non-gray radiation (ANSYS FLUENT Theory Guide 2011), can be written as:

$\frac{d I_{\lambda}(\vec{r}, \vec{s})}{d s}+\left(k_{\lambda}+\sigma_{s}\right) I_{\lambda}(\vec{r}, \vec{s})=k_{\lambda} n^{2} \frac{\sigma_{s} T^{4}}{\pi}+\frac{\sigma_{s}}{4 \pi} \int_{0}^{4 \pi} I_{\lambda}\left(\vec{r}, \vec{s}^{\prime}\right) \Phi\left(\vec{s} \cdot \vec{s}^{\prime}\right) d \Omega^{\prime}$

where $\lambda$ is the wavelength, $\vec{r}$ is the position vector, $\vec{s}$ and $\vec{s}^{\prime}$ are the direction vector and the scattering direction vector, $I$ is the radiation intensity which depends on position $\vec{r}$ and direction $\vec{s}, \sigma_{s}$ is the scattering coefficient, $n$ is the refractive index and $\Omega^{\prime}$ is the solid angle. The scattering phase function $\Phi$ and the refractive index $n$ are assumed independent of the wavelength.

The chosen time step is $0.005 \mathrm{~s}$ and the total time studied is slightly over $500 \mathrm{~s}$ because our experimental results show that the temperature variation of the PET sheet is less than $5 \%$ after that time period. We can therefore consider that a quasi steady state begins at about $\mathrm{t}=500 \mathrm{~s}$ for the heating conditions of our experiment. Furthermore the glassy/rubber transition of the PET sheet is observed after $t \approx 500 \mathrm{~s}$ in these experiments. As the aim of our study is to model the temperature distribution in the PET samples till the glassy/rubber transition, we are going to focus our analysis of the temperature distribution in the PET samples at $\mathrm{t}=500$ to $550 \mathrm{~s}$. Using the discrete ordinate radiation model, the solution accuracy and the solving speed depend on the angular discretization (ANSYS FLUENT Theory Guide 2011). In our 2D calculations, due to the symmetry, the angular space $\pi$ is discretized into $2 N_{\phi}$ solid angles. Different values of the angular discretization number, $N_{\phi}$, are tested to observe their effect. The accuracy of the temperature profile in the PET sample increases if the value of $N_{\phi}$ 
grows; but also increases the cost of the computation. Indeed the radiation heat transfer calculation is very time-consuming with Fluent, even for a 2D model. For instance, for the used mesh, if $N_{\phi}$ is too small ( $N_{\phi}<10$ ), oscillations of the temperature field appear along the side of the sheet and the CPU time for one full simulation is over 20 days on a quadricore PC (Pentium IV, 2.99GHz). If $N_{\phi}$ equals 60 , it leads to a smooth temperature distribution along the side of the PET sheet, but the computational time is estimated to 130 days. Therefore, due to the calculation times estimated in table 2 , we choose $N_{\phi}$ equal to 30 as a best compromise between accuracy and a reasonable computational time.

\section{II.2 Computation of the convective heat transfer coefficient}

Figure 2 shows the velocity vector field and the streamlines of the flow velocity at $550 \mathrm{~s}$ when the system is in the quasi steady state. The dark vectors indicate low speeds, and the green, yellow and red ones indicate higher speeds (the maximum magnitude is $0.675 \mathrm{~m} / \mathrm{s}$ ). The hot lamps and the PET sheet, heated by the IR flux, generate an increase of the air temperature near them and three vertical boundary layers develop along the lamps and the both sides of the PET sheet. Thus free convection vertical flows appear in these boundary layers, with the strongest one along the lamps. Consequently, to feed the boundary layers along the lamps and the PET sheet, cold air suction from the outside of the computational domain is observed. Air enters in the enclosure from the central part of the open vertical boundary, on the right. On its upper part, the air heated by the lamps and the PET sheet leaves the apparatus at high speed. On its bottom part, an outward flow at low velocity is observed. It is driven by the viscous traction of the main flow. One can also see a complex flow between the lamps and the PET sheet: two air recirculation loops arise, one much larger near the lamps and the other much thinner near the sheet.

One can observe from the zoom picture on the right of Fig. 3 that the temperature in the PET sheet is strongly influenced both by the radiative flux received from the lamps and the 
convective heat transfer with air. The temperature is the lowest in the bottom part of the sheet because the air natural convection permanently brings fresh air at this place. In Ansys/Fluent, the convective heat transfer coefficient at walls, $h$, is computed from the following definition discretized by finite differences:

$$
h=\frac{\left.k_{a} \frac{\partial T}{\partial n}\right|_{w, a}}{T_{r e f}-T_{w}}
$$

where $k_{a}$ is the air thermal conductivity, $n$ is the direction normal to the wall and the reference temperature $T_{\text {ref }}$ is chosen as the ambient temperature $T_{\infty}=293 \mathrm{~K}$. Indeed, as shown in Fig. 3, the air temperature varies between $293 \mathrm{~K}$ and less than $297 \mathrm{~K}$ in all the central part of the "chimney" between the wall with the IR lamps and the PET sheet wall, and on the right of the PET sheet, outside the boundary layers.

The local heat transfer coefficient $h$ along the front surface of the PET sheet is calculated in the Ansys/Fluent simulation at each time step to follow its evolution. From $t=400 \mathrm{~s}$, the values of $h$ no longer change. As shown in Fig. 4 at $t=550 \mathrm{~s}, h$ approximately varies from 12 to 8 $\mathrm{W} / \mathrm{m}^{2} \mathrm{~K}$ on average from the bottom to the top of the sheet. The $h$ oscillations in Fig. 4 are due to the $T_{w}$ oscillations in the definition (7) caused by a slightly too low resolution of $N_{\phi}$ as explained at the end of section II.1. To smooth these oscillations, the following function is used to interpolate the more or less linear evolution of the heat transfer coefficient $h$ :

$$
h=h_{0}-\frac{\Delta h}{L} y
$$

where $\Delta h / L=28 \mathrm{~W} / \mathrm{m}^{3} . \mathrm{K}$ and $h_{0}=12 \mathrm{~W} / \mathrm{m}^{2} . \mathrm{K}$.

One can then compare equation (8) with the $h$ correlation proposed in Bejan (1995) equation 4.110, valid at Prandtl number $\operatorname{Pr}=0.71$ (air) for steady laminar natural convection along a vertical wall heated at constant heat flux: 
$h=\frac{k_{a} N u}{y}=0.55 \cdot\left(k_{a}^{4} \frac{g \beta}{v \alpha} q\right)^{1 / 5} y^{-1 / 5}$

where $N u$ is the Nusselt number, $y$ the coordinate along the vertical wall and $g$ the gravitational acceleration. $\beta, \alpha$ and $v$ are the coefficient of thermal expansion, the thermal diffusivity and the kinematic viscosity of air respectively. $q$ is the average radiative flux density received by the PET sheet from the IR lamps. Both $q$ and the wall temperature $T_{w}$ (necessary to estimate the thermal properties) are obtained from the result of the Ansys/Fluent simulation: $q=1900 \mathrm{~W} / \mathrm{m}^{2}$ and $T_{w}$ is given in Table 3 with the values of the heat transfer coefficient $h$ from the numerical approach (Equation 8) and the one from equation (9), in the bottom, middle and top of the front surface of the PET sheet. The relative difference for these 3 values of $h$ varies between 4 and 50\%. That means the heat transfer coefficient $h$ based on the correlation equation (9) cannot be used in the present configuration. It is therefore necessary to simulate the air natural convection to obtain the convective heat transfer coefficient.

\section{II.3 Validation of $\boldsymbol{h}$ for a 3D simulation of the PET sheet alone}

In this section, we present a 3D simulation with Comsol of the heat transfer in the PET sheet alone using a simplified approach to model the effect of the air natural convection. To mimic this effect, the convective heat transfer coefficient $h$ given by Eq. (8) is introduced in the thermal boundary conditions of this numerical simulation. Thanks to this simplified model for convection, using the radiative flux modeled in (Luo et al. 2013) we both improve the simulation accuracy and limit the computational cost.

The 3D 'General Heat Transfer' model of Comsol Multiphysics 3.5 software was chosen to analyze the heat transfer by conduction, convection and radiation. This model is able to perform a transient analysis and to be adapted by user's own expression for the thermal properties and boundary conditions. Compared with the 250000 cells of the $2 \mathrm{D}$ simulation 
with Ansys/Fluent, only 61000 linear tetrahedral elements have been used in this 3D computation with Comsol limited to the PET sheet. The initial temperature is $300 \mathrm{~K}$. The time step is $0.1 \mathrm{~s}$ and the total time studied is over $500 \mathrm{~s}$.

Figure 5 shows the comparison between the temperature of the rear surface at quasi-steady state measured by the thermal camera and the one coming from the simulation. The mean difference $\left(\sum_{i=1}^{n=36}\left|\Delta T_{i}\right| / T_{i}\right) / n$ does not exceed 5\%. This allows us to consider with confidence the calculations for more complicated geometries, such as that of a cylindrical preform rotating in front of the lamps during the heating phase.

\section{Modelling of the infrared heating of the PET preform}

The complete calculation of the fluid flow and convective and radiative heat transfer using Ansys/Fluent takes a lot of CPU time and is not adapted to the simulation of the IR heating of rotating preforms in an industrial context. Therefore, in the case of the PET cylindrical preforms, we have chosen to make a 3D calculation of the heat transfer in the preform only, and to model the radiative and convective heat transfer with its environment in a simplified way, as presented in the following subsections.

\section{III.1 Computation of the incident radiation on the PET preform}

Before performing the thermal simulation of the IR heating of the preform, the incident radiation must be calculated and then implemented in the software Comsol. The infrared radiation received by the preform can be estimated from a simple modeling by integrating the spectral energy and by taking into account the view (or form) factors between the lamps and the preform. Figure 6 a presents the geometry of the lamps and the preform. Eight identical IR lamps (radius $r=2 \mathrm{~mm}$ and length $L=185 \mathrm{~mm}$ ) are modeled as cylinders separated by a distance $\mathrm{d}=18.6 \mathrm{~mm}$ (Fig. 6b). 
The amount of the radiation energy that comes from the surface element $d A$ ' at the collocation point $M^{\prime}$ and reaches the surface element $d A$ at the collocation point $M$ is first calculated. Firstly, one focuses on the cylindrical part of the preform. The coordinates of the points $\mathrm{M}$ and $\mathrm{M}$ ' are:

$$
\begin{aligned}
& M^{\prime}\left\{\begin{array}{l}
x^{\prime}=r \cos \varphi+x_{L} \\
y^{\prime} \\
z^{\prime}=d-r \sin \varphi
\end{array}, \quad M\left\{\begin{array}{l}
x \\
y=R \cos \alpha \\
z=R \sin \varphi
\end{array}\right.\right. \\
& \overrightarrow{e_{r^{\prime}}}=(\cos \varphi, 0,-\sin \varphi) \\
& \hline e_{R}=(0, \cos \alpha, \sin \alpha)
\end{aligned}
$$

where $x_{L}$ is the lamp coordinate along the axis $x$.

The path vector from $M^{\prime}$ to $M$ is denoted by $\vec{w}$. Assuming that the radius $r$ is negligible compared to the distance $d(r<<d)$, this vector can be written as follow:

$$
\vec{w}=\frac{\overrightarrow{M^{\prime} M}}{M M^{\prime}}=\left\{\begin{array}{l}
\frac{x-x^{\prime}}{M M^{\prime}}=\frac{x-r \cos \varphi-x_{L}}{M M^{\prime}} \approx \frac{x-x_{L}}{M M^{\prime}} \\
\frac{y-y^{\prime}}{M M^{\prime}}=\frac{R \cos \alpha-y^{\prime}}{M M^{\prime}} \\
\frac{z-z^{\prime}}{M M^{\prime}}=\frac{z-d+r \sin \varphi}{M M^{\prime}} \approx \frac{z-d}{M M^{\prime}}
\end{array}\right.
$$

where $M M^{\prime}=\sqrt{\left(x-x_{L}\right)^{2}+\left(y-y^{\prime}\right)^{2}+(z-d)^{2}}$.

The two angles $\theta^{\prime}$ and $\theta$ represent respectively, the angle between the direction normal to the lamp surface $\overrightarrow{n^{\prime}}$ at point $\mathrm{M}^{\prime}$ and the path direction $\vec{w}$; the angle between the direction normal to the PET sheet $\vec{n}$ at point $\mathrm{M}$ and the path direction $\vec{w}$ :

$$
\left\{\begin{array}{l}
\cos \theta=-\vec{w} \cdot \overrightarrow{e_{R}}=-\frac{\left(y-y^{\prime}\right) \cos \alpha+(z-d) \sin \alpha}{\left\|M M^{\prime}\right\|^{2}}=-\frac{\left(y-y^{\prime}\right) \frac{y}{R}+(z-d) \frac{z}{R}}{\left\|M M^{\prime}\right\|^{2}}=-\frac{\left(y-y^{\prime}\right) y+(z-d) z}{\left\|M M^{\prime}\right\|^{2} R} \\
\cos \theta^{\prime}=\vec{w} \cdot \overrightarrow{e_{r^{\prime}}}=\frac{\left(x-x_{L}\right) \cos \varphi-(z-d) \sin \varphi}{\left\|M M^{\prime}\right\|^{2}}
\end{array}\right.
$$

The amount of the radiation heat energy can be written in the following way: 


$$
\begin{aligned}
& d Q_{\text {lamp } \rightarrow d A}=\int_{\lambda_{1}}^{\lambda_{2}} i_{\lambda b} \varepsilon_{\lambda} d_{\lambda} \cdot \int_{\varphi=0}^{\pi} \int_{y^{\prime}=-l / 2}^{l / 2}\left(\frac{\left[\left(y^{\prime}-y\right) y+(d-z) z\right]}{R} \cdot\left[\left(x-x_{L}\right) \cos \varphi+(d-z) \sin \varphi\right]\right) \frac{d A}{\left\|M M^{\prime}\right\|^{4}} r d \varphi d y^{\prime} \\
& d Q_{\text {lamp } \rightarrow d A}=\int_{\lambda_{1}}^{\lambda_{2}} i_{\lambda b} \varepsilon_{\lambda} d_{\lambda} \cdot r \cdot \int_{\varphi=0}^{\pi} \frac{\left[\left(x-x_{L}\right) \cos \varphi+(d-z) \sin \varphi\right]}{R} d \varphi \cdot \int_{y^{\prime}=-l / 2}^{l / 2} \frac{\left(y^{\prime}-y\right) y+(d-z) z}{\left\|M M^{\prime}\right\|^{4}} d y^{\prime} \cdot d A \\
& d Q_{\text {lamp } \rightarrow d A}=\int_{\lambda_{1}}^{\lambda_{2}} i_{\lambda b} \varepsilon_{\lambda} d_{\lambda} \frac{r \cdot 2(d-z)}{R} \int_{y^{\prime}=-l / 2}^{l / 2} \frac{\left(y^{\prime}-y\right) y+(d-z) z}{\left\|M M^{\prime}\right\|^{4}} d y^{\prime} \cdot d A
\end{aligned}
$$

where $\lambda$ is a given wavelength between 0.2 and $10 \mu \mathrm{m}$ and $\varepsilon_{\lambda}$ is the average tungsten emissivity equal to 0.26 for a wavelength between 0.2 and $10 \mu \mathrm{m}$ (Bordival 2009). The emissive power for a blackbody $i_{\lambda}^{b}$ is given by Planck's law:

$$
i_{\lambda}^{b}=\frac{2 C_{1}}{\lambda^{5}\left(e^{C_{2} / \lambda T_{f l l}}-1\right)}
$$

where $C_{1} \approx 1.19 \cdot 10^{8} \mathrm{~W} \cdot \mathrm{m}^{-2} \cdot \mu \mathrm{m}^{4}$ and $C_{2} \approx 14388 \mu \mathrm{m} . \mathrm{K}$. We assume that the temperature of the filament is uniform and equals to $T_{f i l}=1700 \mathrm{~K}$ (Monteix 2001).

Finally, the intensity per unit area of the incident radiation can be written as follow:

$$
\phi_{S}(M)=\frac{d Q_{\text {lamp } \rightarrow d A}}{d A}=\int_{\lambda_{1}}^{\lambda_{2}} \frac{2 C_{1} \varepsilon_{\lambda}}{\lambda^{5}\left(e^{C_{2} / \lambda T_{f l l}}-1\right)} d_{\lambda} \frac{r \cdot 2(d-z)}{R} \int_{y^{\prime}=-l / 2}^{l / 2} \frac{\left(y^{\prime}-y\right) y+(d-z) z}{\left\|M M^{\prime}\right\|^{4}} d y^{\prime}
$$

The incident radiation on the point $M$ depends on its position with respect to the points $A$ and $B$ of the lamp $\left(y^{\prime}= \pm l / 2\right)$. There are three cases:

- Point $M$ can receive the radiation from point $A$ to point $B$. The interval of integration for $\phi_{S}(M)$ is $[-l / 2, l / 2]$.

- Point $M$ receives no radiation from the lamp ( $\mathrm{M}$ is located in the rear part of the preform). In this case, the incident radiation on point $M$ is zero.

- Point $M$ can get only a part of the total radiation from point $A$ to point $B$. That means that point $M$ can receive the radiation from the interval $A D$ or $B D$, where $D$ is an 
intermediate point of the lamp. In this case, points $A$ and $B$ are on the opposite sides of the tangent plane of the tube at point $M$.

In the third case, it is necessary to find the intersection D between the tangent plane and the lamp. The equation of the tangent plane at the point $M\left(x_{M}, y_{M}\right)$ and the line of the lamp can be written:

$\left(z-z_{M}\right) z_{M}+\left(y-y_{M}\right) y_{M}=0$

$$
\left\{\begin{array}{l}
z=d \\
x=x_{L} \\
-l / 2 \leq y \leq l / 2
\end{array}\right.
$$

Therefore, the coordinates of $\mathrm{D}$ can be calculated as:

$$
\begin{aligned}
& \left(z-z_{M}\right) z_{M}+\left(y-y_{M}\right) y_{M}=0 \\
& \left\{\begin{array} { l } 
{ ( z - z _ { M } ) z _ { M } + ( y - y _ { M } ) y _ { M } = 0 } \\
{ z = d } \\
{ x = x _ { L } }
\end{array} \Rightarrow \left\{\begin{array}{l}
z_{D}=d \\
x_{D}=x_{L} \\
y_{D}=\frac{\left(z_{M}-d\right) z_{M}}{y_{M}}+y_{M}
\end{array}\right.\right.
\end{aligned}
$$

Then we consider the semi-spherical part of the preform. After a calculation similar to that of the cylindrical part, the intensity per unit area of the incident radiation at the point $M$ is:

$\phi_{S}(M)=\frac{d Q_{\text {lamp } \rightarrow d A}}{d A}=\int_{\lambda_{1}}^{\lambda_{2}} \frac{2 C_{1} \varepsilon_{\lambda}}{\lambda^{5}\left(e^{C^{2} / \lambda T_{f l l}}-1\right)} d_{\lambda} \frac{r \cdot 2(d-z)}{R} \int_{y^{\prime}=-l / 2}^{l / 2} \frac{\left(x-x_{L}\right)\left(x_{O_{1}}-x\right)+\left(y^{\prime}-y\right) y+(d-z) z}{\left\|M M^{\prime}\right\|^{4}} d y^{\prime}$ 
There are also three cases as in the previous case. The coordinates of the intersection $D$ are given in equation 18 :

$$
\left\{\begin{array} { l } 
{ ( z - z _ { M } ) z _ { M } + ( y - y _ { M } ) y _ { M } = 0 } \\
{ z = d } \\
{ x = h _ { \text { lamp } } }
\end{array} \Rightarrow \left\{\begin{array}{l}
z_{D}=d \\
x_{D}=h_{\text {lamp }} \\
y_{D}=\frac{\left(h_{\text {lamp }}-x_{M}\right)\left(x_{M}-x_{O_{1}}\right) z_{M}+\left(z_{M}-d\right) z_{M}}{y_{M}}+y_{M}
\end{array}\right.\right.
$$

From the calculation of the incident radiation intensity on the cylindrical or semi-spherical part, one obtains the incident heat flux on the outer surface of the preform (Fig. 7). One can see that the incident radiation intensity reaching the outer surface of the PET preform is not uniform. At the central zone, the incident heat flux can reach $2500 \mathrm{~W} / \mathrm{m}^{2}$. In the semispherical part, it drops quickly with the depth because of the geometry (it reaches zero at the deepest point).

The incident heat flux is first calculated in Cartesian coordinates $(\mathrm{x}, \mathrm{y}, \mathrm{z})$ then transferred in cylindrical coordinates $(\mathrm{r}, \theta, \mathrm{z})$ to impose the interpolated flux in the simulation. According to the distribution and the values of the incident heat flux shown in Fig. 7, the exponential function below (Eq. 21) is chosen for the interpolation in order to guarantee a positive value of the flux at all points of the preform:

$q_{f l u x}=a \exp \left(b \theta^{2}+c \theta+d z^{2}+e z+f\right)$

where: $a=2.43\left(\mathrm{~W} / \mathrm{m}^{2}\right), b=-0.86, c=-0.0056, d=6.45\left(\mathrm{~m}^{-2}\right), e=-92.61\left(\mathrm{~m}^{-1}\right), f=0.61$

The least squares method has been used to fit the flux calculated and determine the parameters of the interpolation equation. From Fig. 7, we compare the intensity of the incident radiation calculated and the one interpolated. In the cylindrical part, the maximum difference between these two fluxes is less than $0.1 \%$; it is equal to $5 \%$ in the semi-spherical region. 


\section{III.2 3D simulation of the IR heating of a PET preform and experimental comparison}

We focus now on the modeling of the temperature distribution in a preform heated by IR lamps. The preform rotates at a speed of 8 rounds / minute in front of the IR lamps, in order to obtain a homogeneous heating in the azimuthal direction of the preform. In the experimental result, 60 points on the outer surface of the preform are measured by the thermal camera to follow the evolution of the temperature. Figure $8 . b$ shows the outside temperature of the preform measured at quasi-steady state.

To take into account the rotation of the preform, the interpolated intensity of the incident radiation of equation (21) is implemented in the simulation by the software Comsol with $\theta=\Omega t$ and $\Omega=8$ rounds / minute. Figures 8 .a and 8.c show the temperature on the outer surface of the preform at quasi-steady state obtained by the numerical solutions: in Fig. 8.a the convection heat transfer coefficient $h$ is constant and equal to $12 \mathrm{~W} / \mathrm{m}^{2} . \mathrm{K}$ and, in Fig. 8.c, the value of $h$ given by the 2D simulation with Ansys/Fluent (Eq. 8). The temperature obtained in the first case is too high in the bottom region (a difference of $15^{\circ}$ between the calculated and measured temperatures) and would lead to an inaccurate evolution of the blown shape of the bottle if this temperature distribution was used as initial condition for a free blowing simulation of a preform. The second case (Fig. 8.c) gives a good representation of the experimental results measured by the camera: in the center region, the mean temperature difference is about $1^{\circ}$; in the spherical region, it is about $5^{\circ}$ and it is $2-3^{\circ}$ near the neck which is very reasonable considering the uncertainties of the process conditions.

Figure 9 shows the evolution of the temperature on 3 points of the outer surface of the preform: in the top region near the neck, in the bottom region near the injection point and in the center region. It compares the results obtained by simulation from Comsol and measured by the camera. For both top and center points, the mean difference between the two curves is 
about $1 \%$. The difference is higher in the beginning of the simulation for the bottom point. This may be due to the interpolation of the IR flux which is under evaluated in the semi spherical region of the preform.

In the simulation results, the preform rotates in front of the IR lamps and that leads to oscillations in the temperature evolution when following a given node. These oscillations can reach $3^{\circ} \mathrm{C}$ above and below the mean temperature. This phenomenon does not appear experimentally because the thermal camera always measures the temperature at the same location in space (i.e. the material point of the preform is not followed by the camera).

Figure 10 shows the temperature distribution after IR heating along the inside and outside surface of the preform. One can observe that the bottom region is not heated enough and the temperature in this region is lower than the glass transition temperature which is equal to about $80^{\circ} \mathrm{C}$. That is because firstly the bottom region is at the same vertical position as the last lamp: the incident radiation in this part is not intense enough; secondly, the bottom region of the preform receives directly the cold air and the effect of the air natural convection is not negligible.

From Fig. 11a of the experimental set-up, one can see that the bottom of the preform is at the same height of the bottom of the lamp. If we perform a free blowing process in this IR heating condition, the semi spherical part of the preform could not be dilated (this can be shown in Fig. 11b).

\section{Conclusions}

The main result of the present study is that the convection heat transfer must be taken into account in the modeling of the IR heating of PET sheets and preforms. Otherwise, the temperature in the PET samples is overestimated and can lead to a wrong modeling of the PET sample behavior in the ISBM process. However, the computational cost to solve a full 3D model of the coupled heat transfer during the ISBM process (taking into account the 
conduction, convection and radiation in and between a PET preform, the IR lamps and the air flow) is so high that it cannot be applied in an industrial context. The aim of this paper is therefore to propose a simplified but consistent modeling of both the convective and radiative heat transfers during the IR heating step of the PET preform that can be solved at a reasonable computational cost. The different steps of this modeling are summed up now.

First, the thermal properties of PET identified in Luo et al. $(2012,2013)$ at a temperature near and slightly above the glass transition temperature, $T_{g}$, are used to conduct a complete $2 \mathrm{D}$ numerical simulation of the convective and radiative heat transfers for the case of the PET sheet with Ansys/Fluent software. This geometry allows to consider a 2D modelling. Second, the heat transfer coefficient $h$ is computed the previous results and a linear interpolation for $h(z)$ is carried out.

Third, we model the IR heating flux for the PET sheet and the $h(z)$ is introduced as a boundary condition in the Comsol software to carry out a 3D simulation of the problem. A good agreement (less than 5\% mean difference) between the experimental and numerical temperature distributions in the PET sheet is obtained. This approach reduces drastically the CPU time needed for calculation.

In order to simulate the IR heating of a rotating preform in front of IR lamps, we have conducted the calculation of IR heating flux coming from the IR lamps in a geometry adapted to the spherical and cylindrical shapes of the PET preform. A 3D numerical simulation has been performed with the interpolated intensity of the incident radiation and a linear distribution of the heat transfer coefficient $h$ to model the natural air convection effect. The numerical temperature distribution on the outer surface of the preform at quasi-steady state fits well (less than $8 \%$ max difference) the experimental results measured by the camera. This approach is much more accurate than the classical use of a constant convection heat transfer coefficient. 
In future works, we intend to implement the temperature distribution of the preform as an initial condition to simulate accurately and reproduce the blowing of the preform as shown and finally simulate the ISBM process. In parallel, the uncertainty of the simplified model for natural air convection is also studied in order to qualify the accuracy of the temperature field prediction.

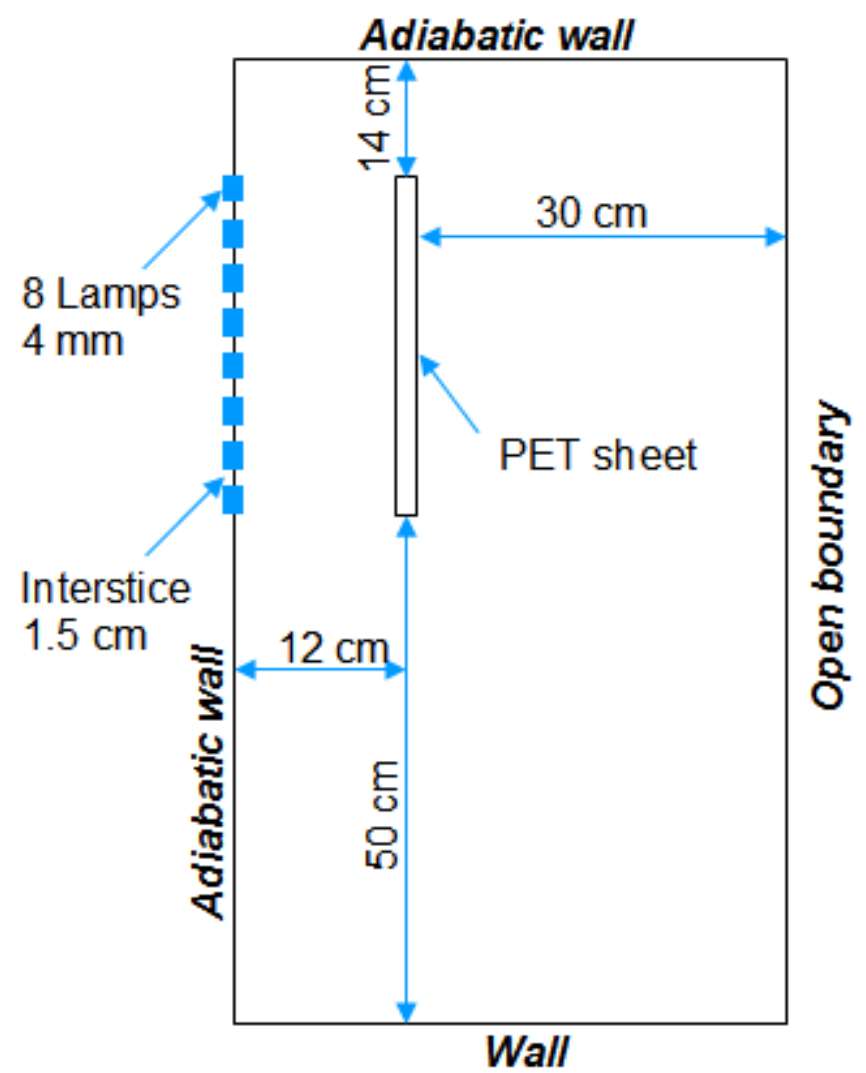

Figure 1. Geometry of the problem 


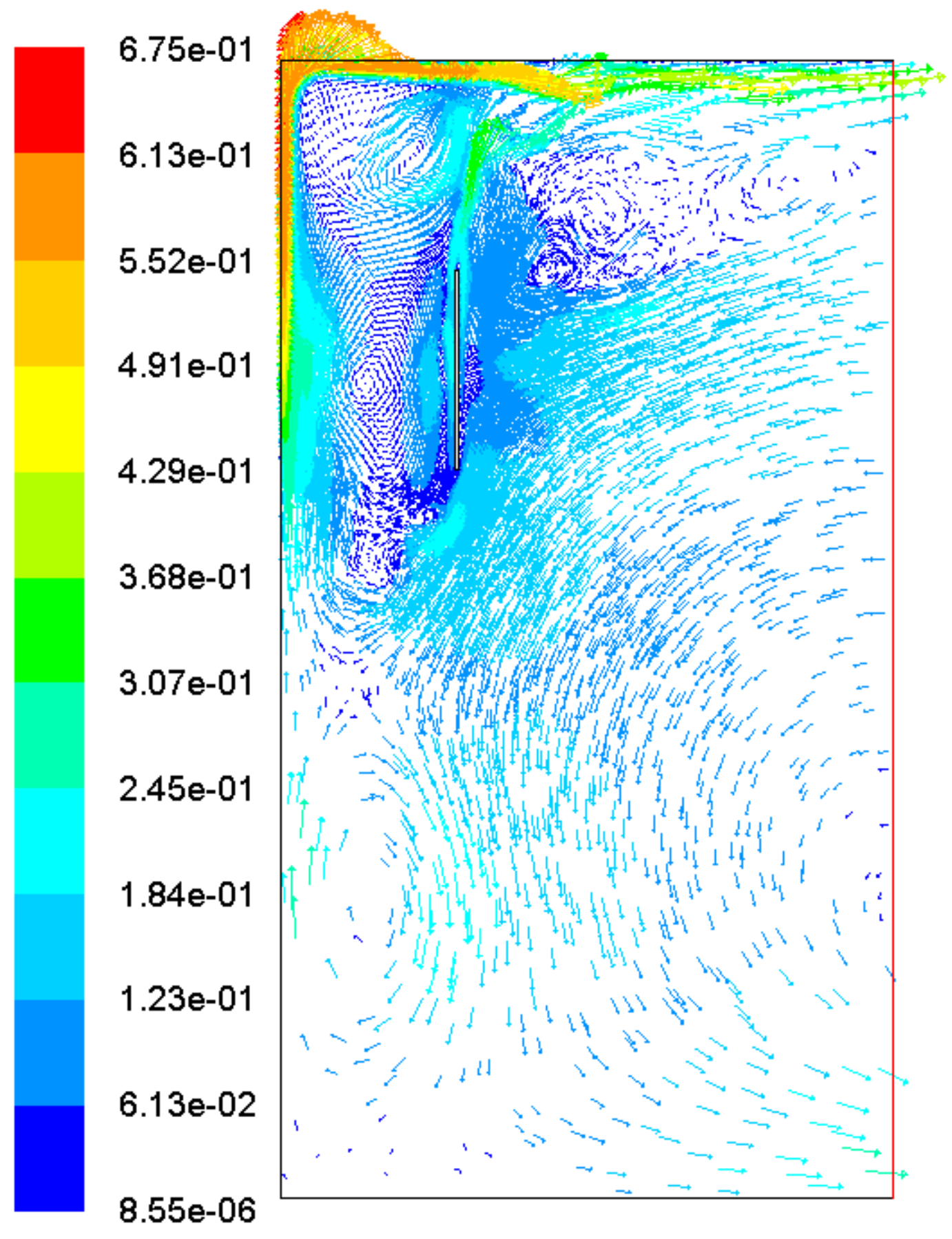




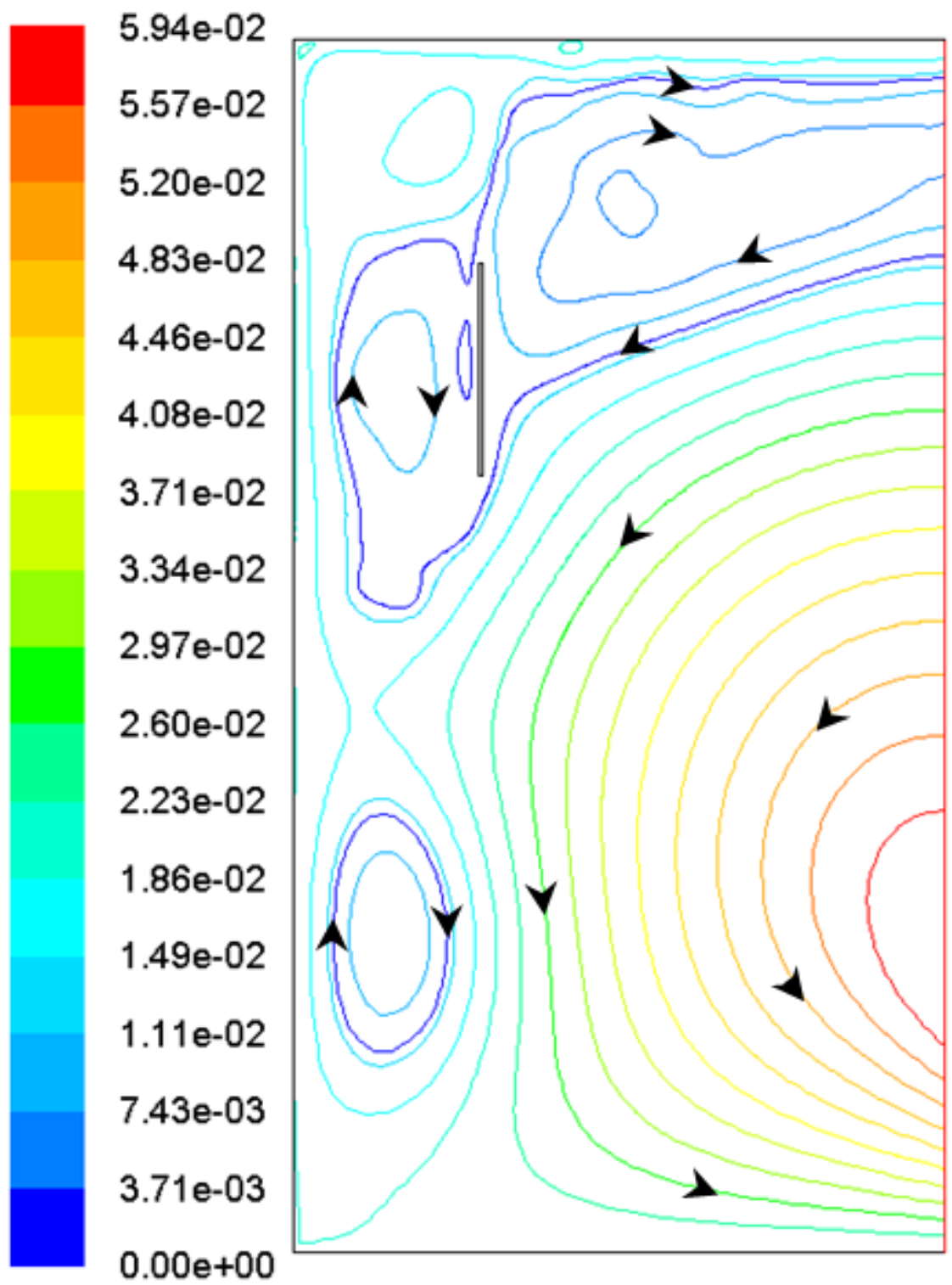

(b)

Figure 2. Results of Ansys/Fluent at time $t=553 \mathrm{~s}$ : (a) Velocity vectors colored by the velocity magnitude; (b) Streamlines 

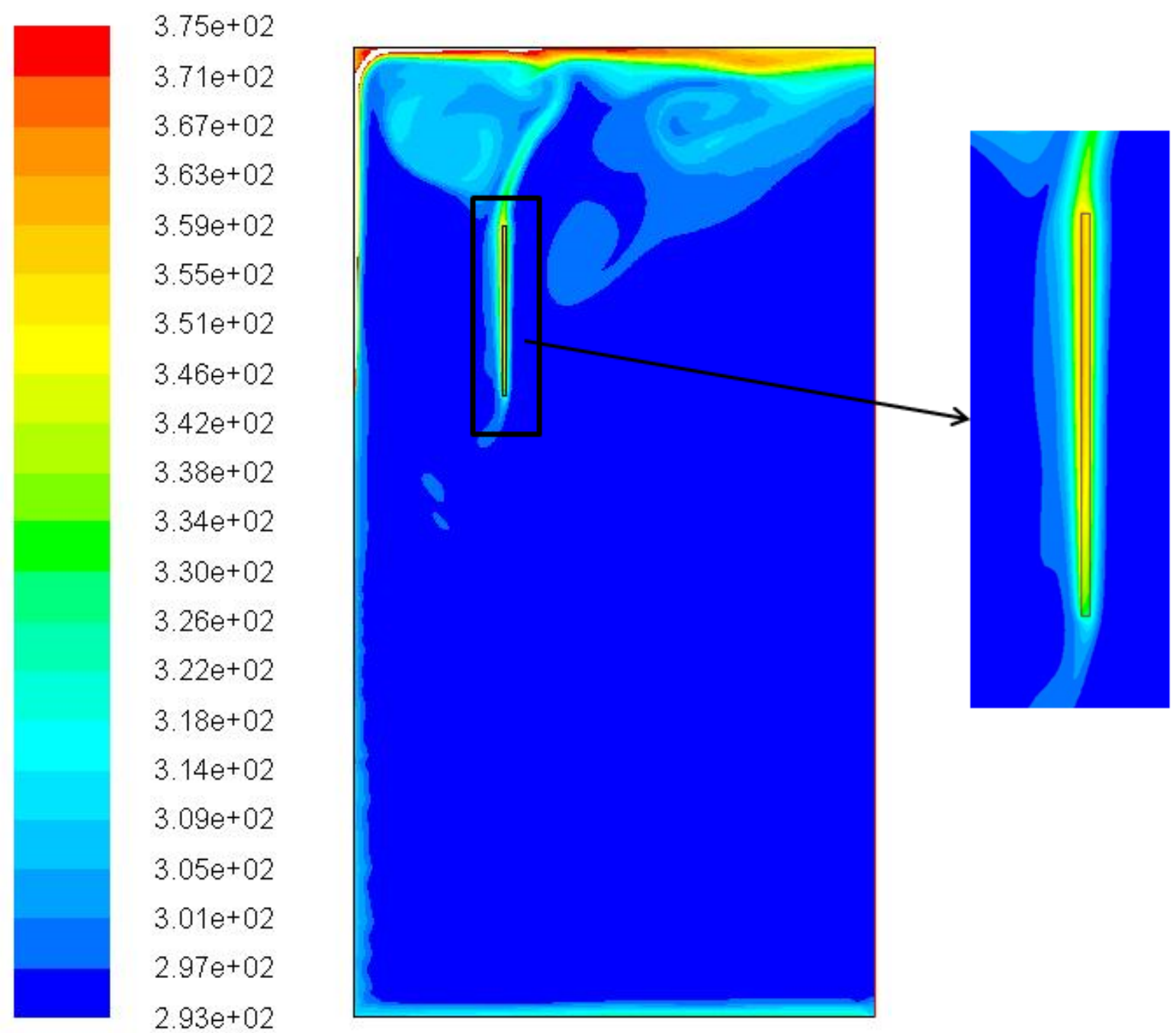

Figure 3. Results of Fluent: the temperature field in the cavity and near the sheet at $553 \mathrm{~s}$ 


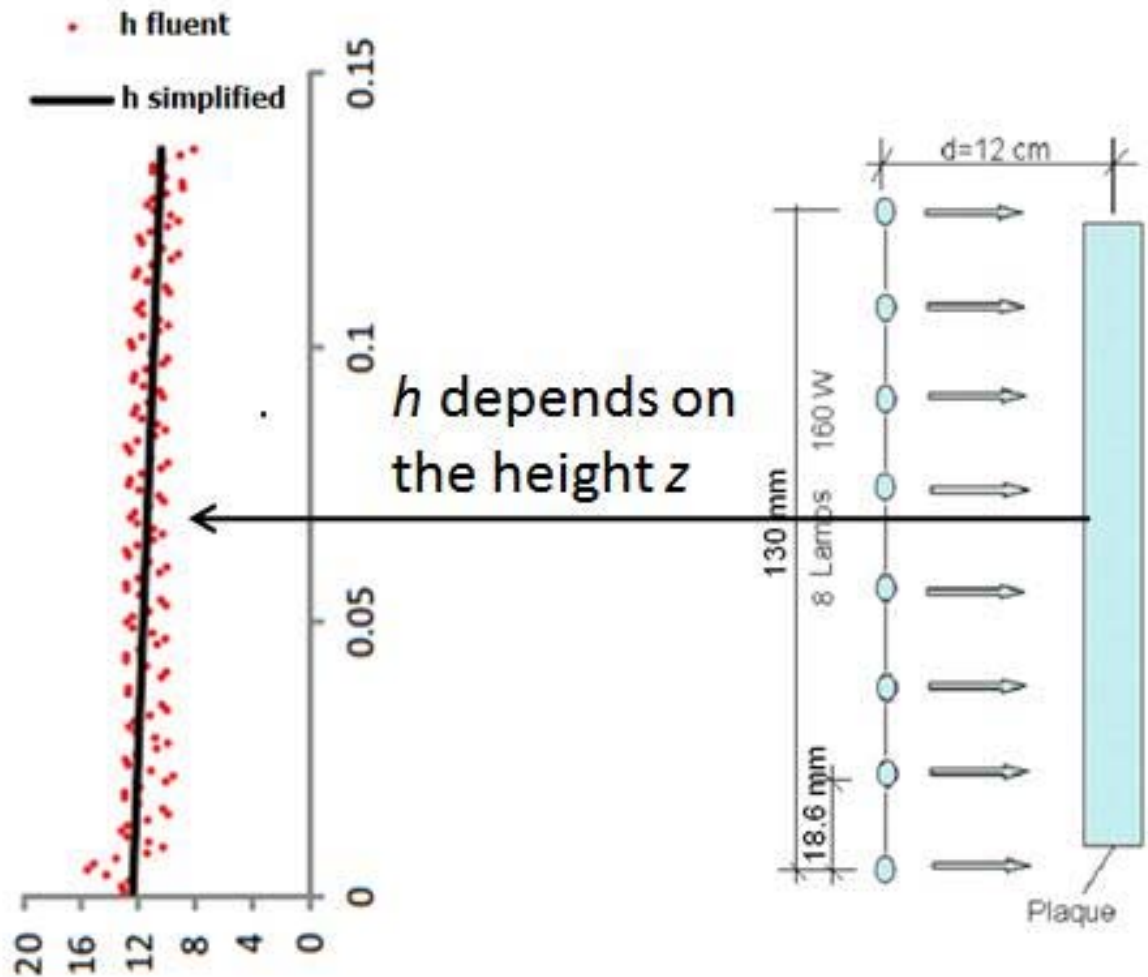

Figure 4. Results of Fluent: the heat transfer coefficient h along the front surface of the PET sheet at time $t=553 \mathrm{~s}$

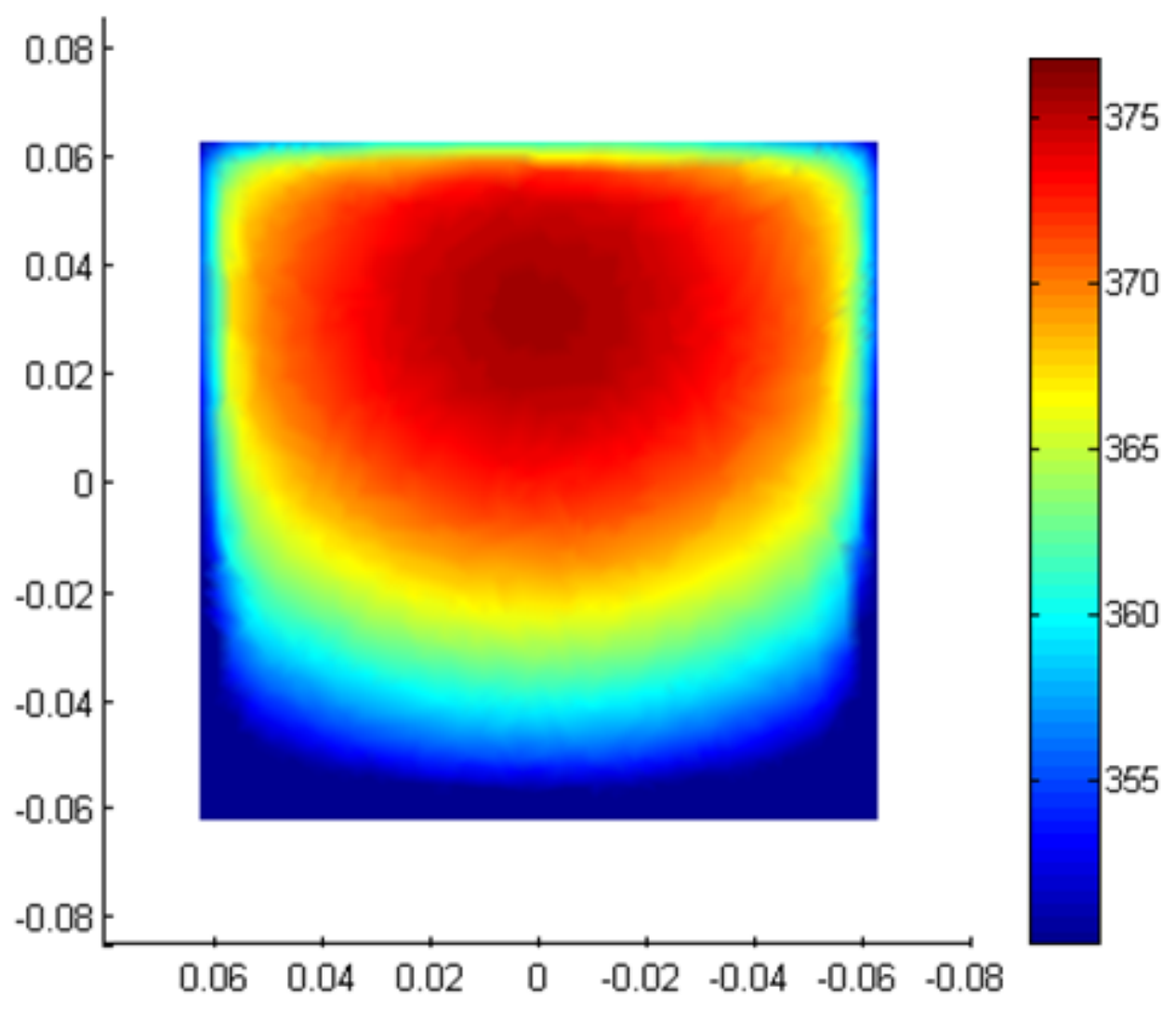




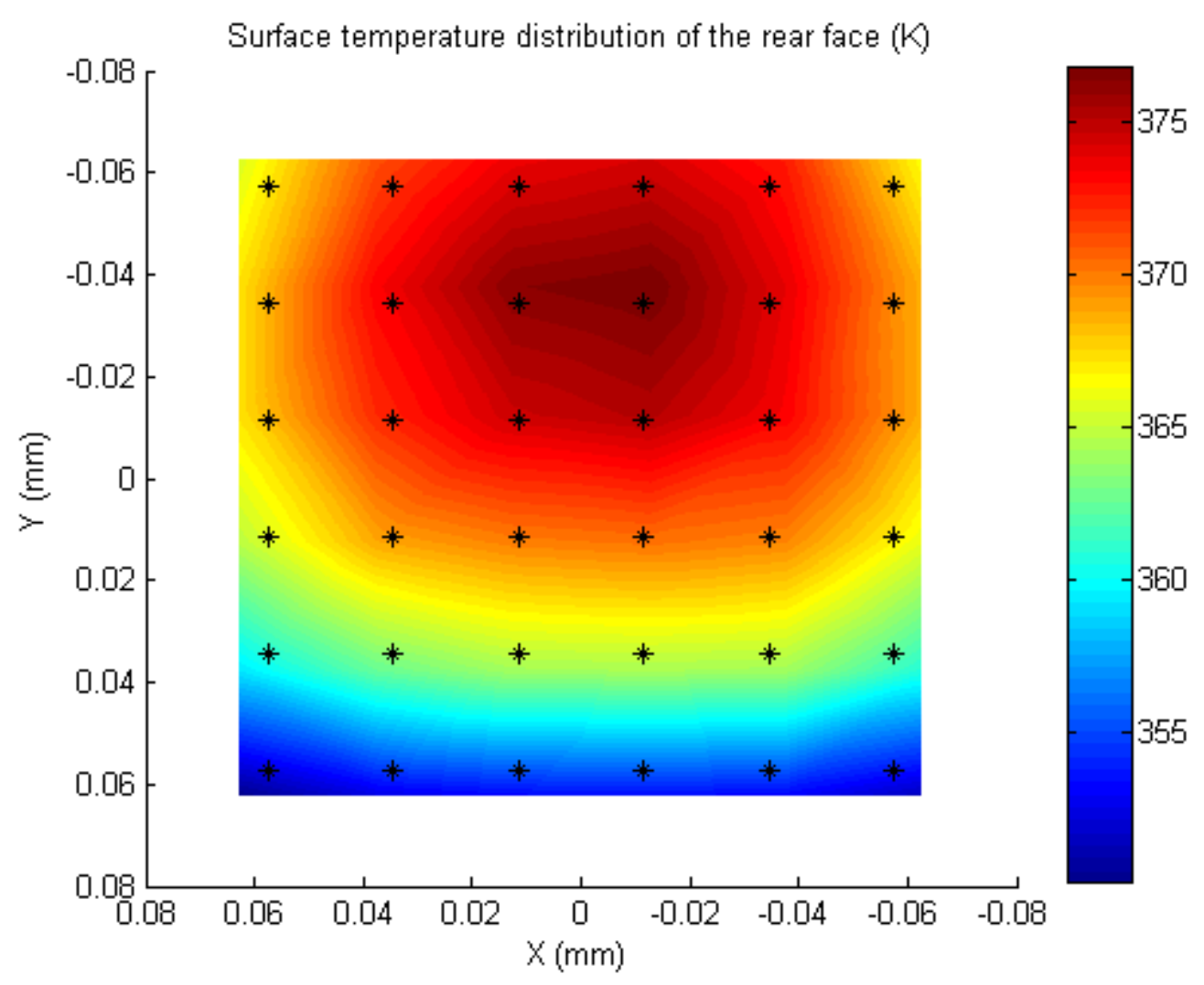

(b)

Figure 5. Temperature of the rear surface of the PET sheet at quasi-steady state: (a) simulation results from Comsol; (b) experimental results from the thermal camera

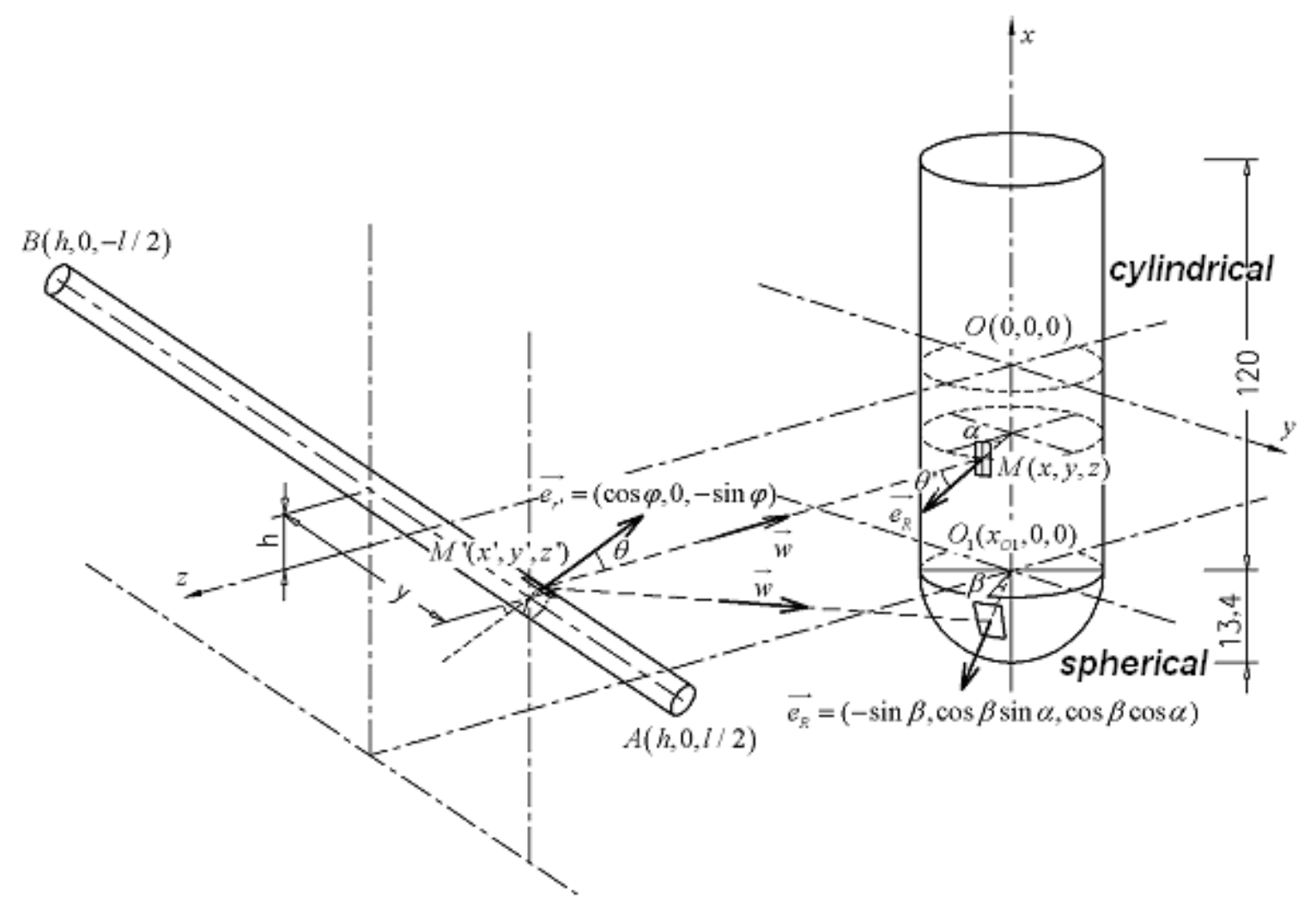

(a) 


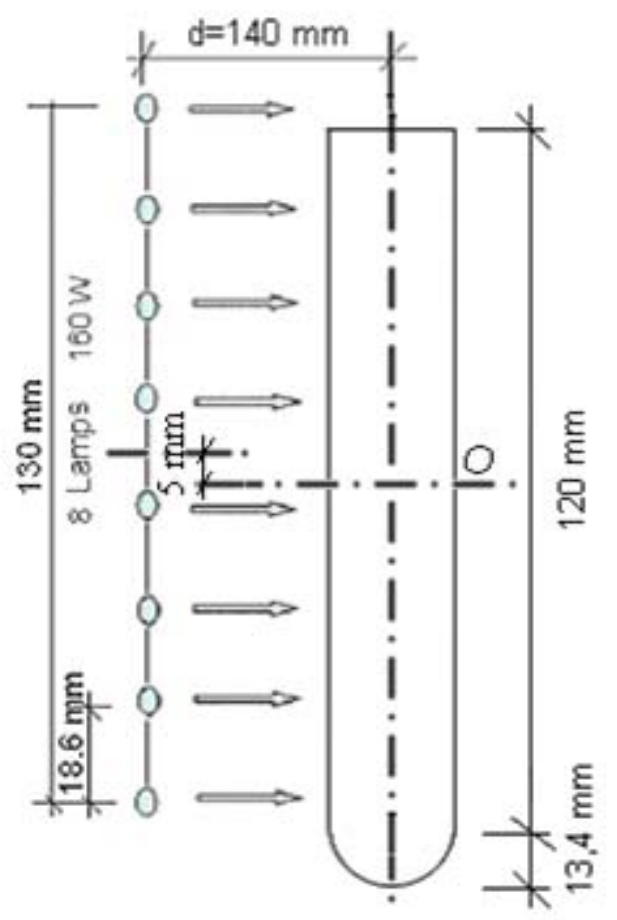

(b)

Figure 6. (a) Geometrical configuration of the lamps and the preform; (b) Position of the lamps

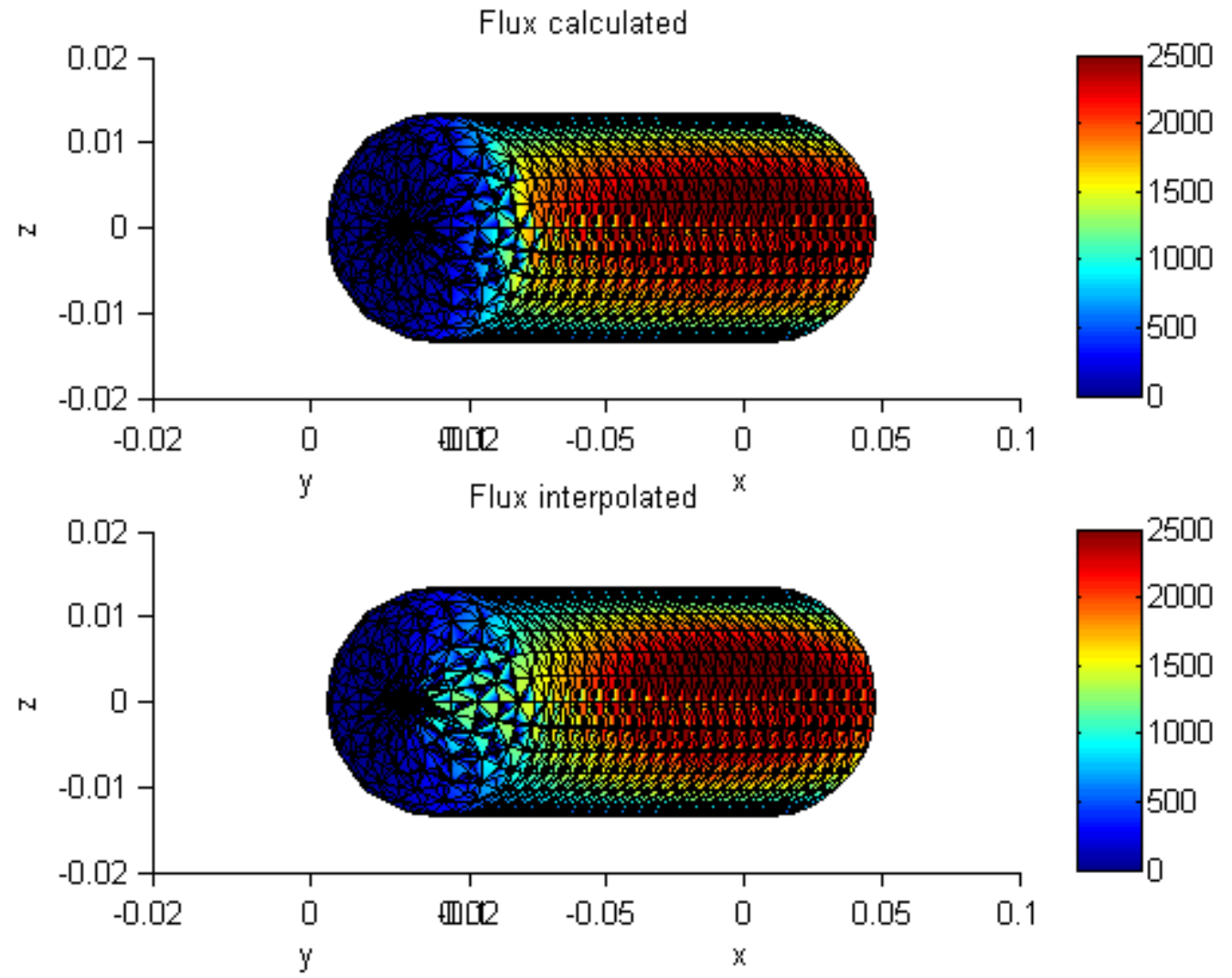

Figure 7. The intensity of the incident radiation on the outer surface of the preform (Visualized by Matlab): calculated (above) VS interpolated (below) 
(a)

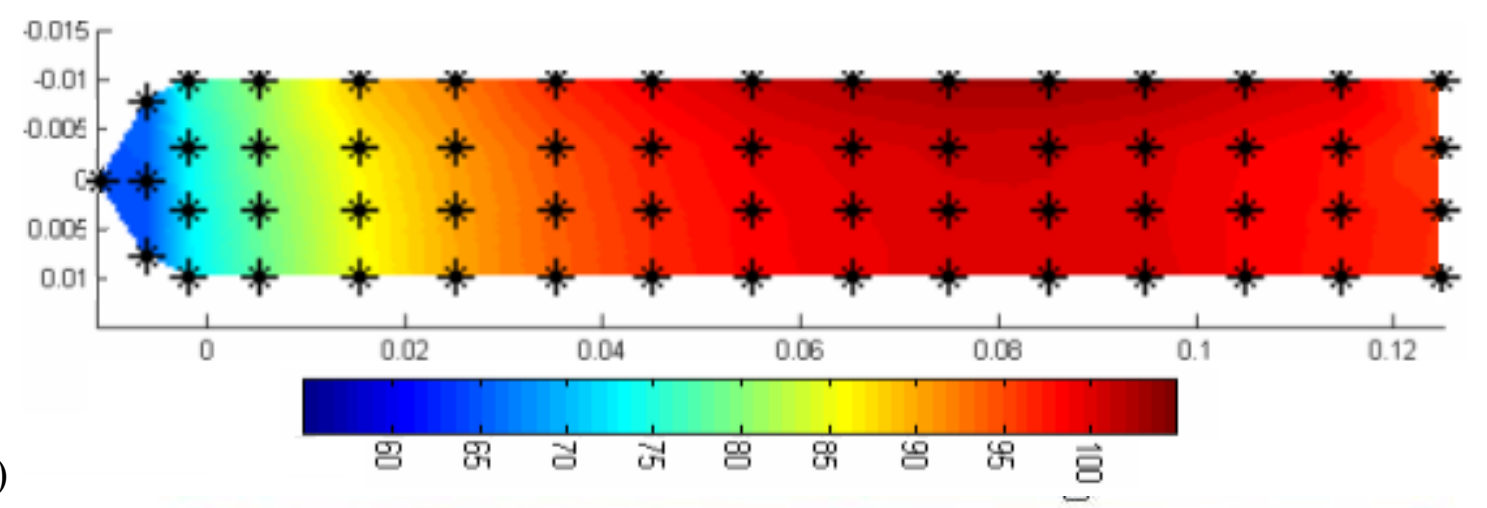

(c)

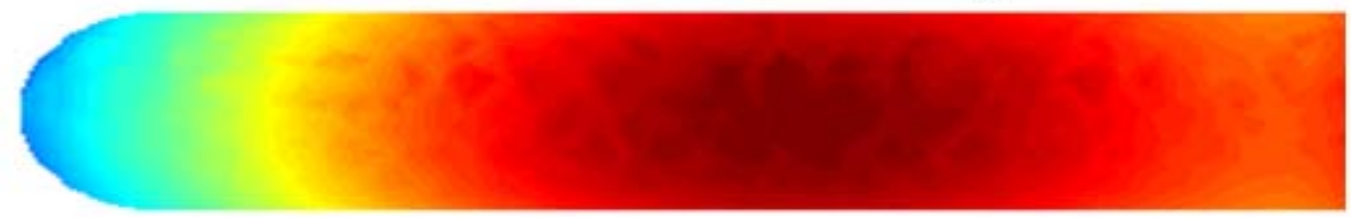

Figure 8. Temperature distribution on the outer surface of the preform at the quasi-steady state: (a) numerical results from Comsol with constant convection heat transfer coefficient;

(b) experimental results from the thermal camera; (c) numerical results from Comsol including the natural convection model

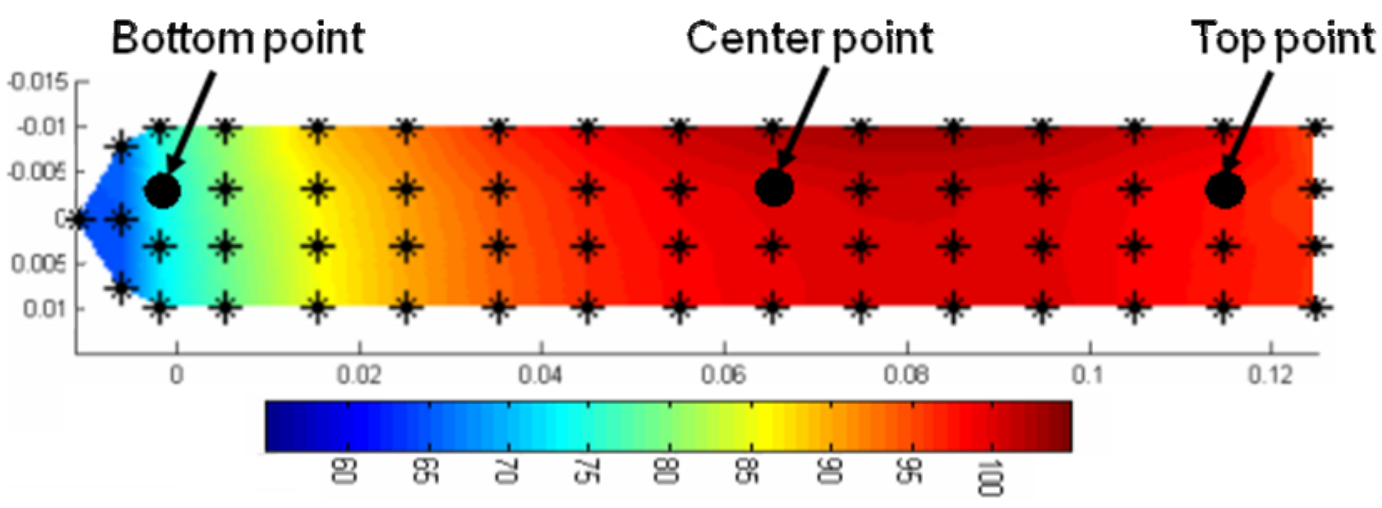




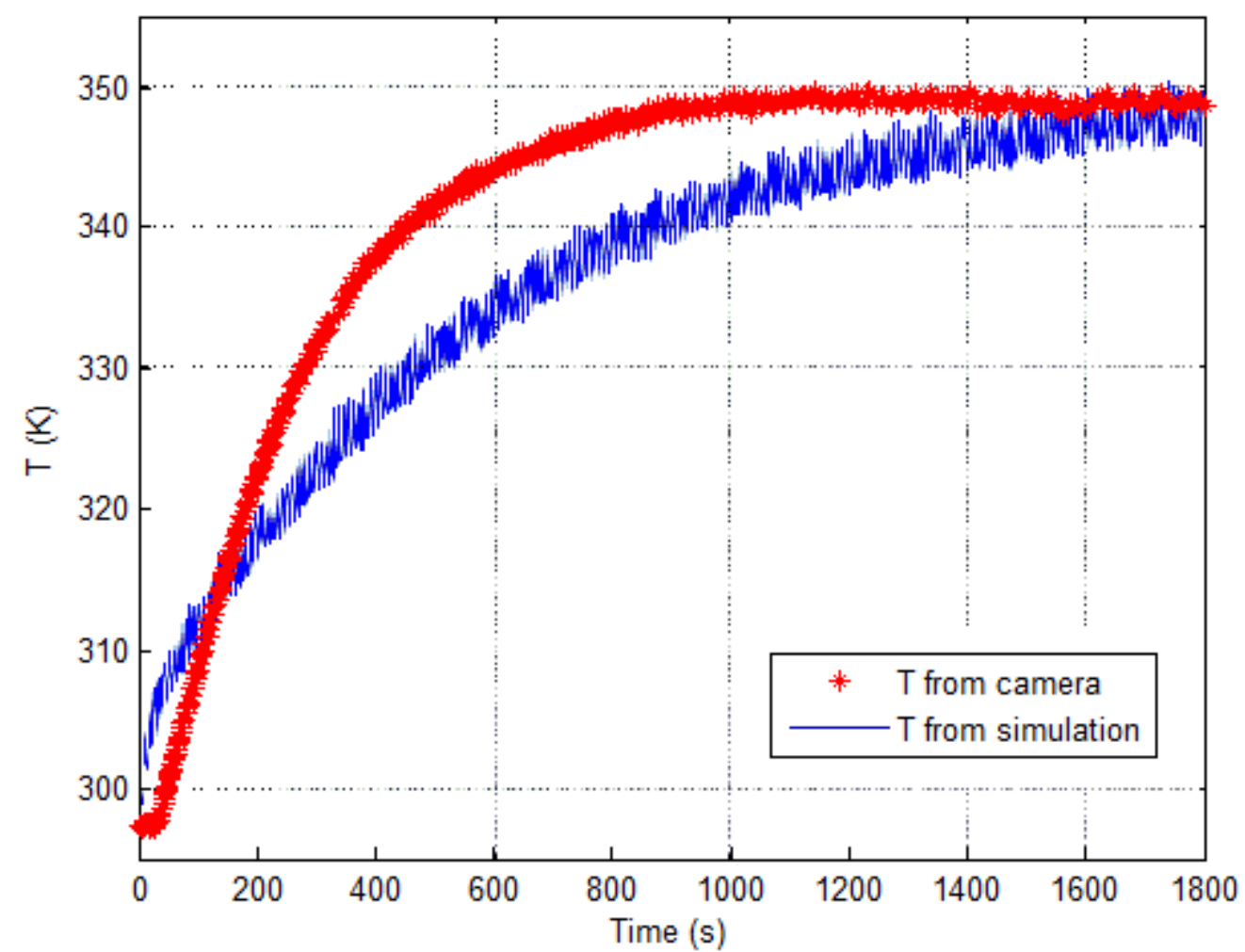

(b)

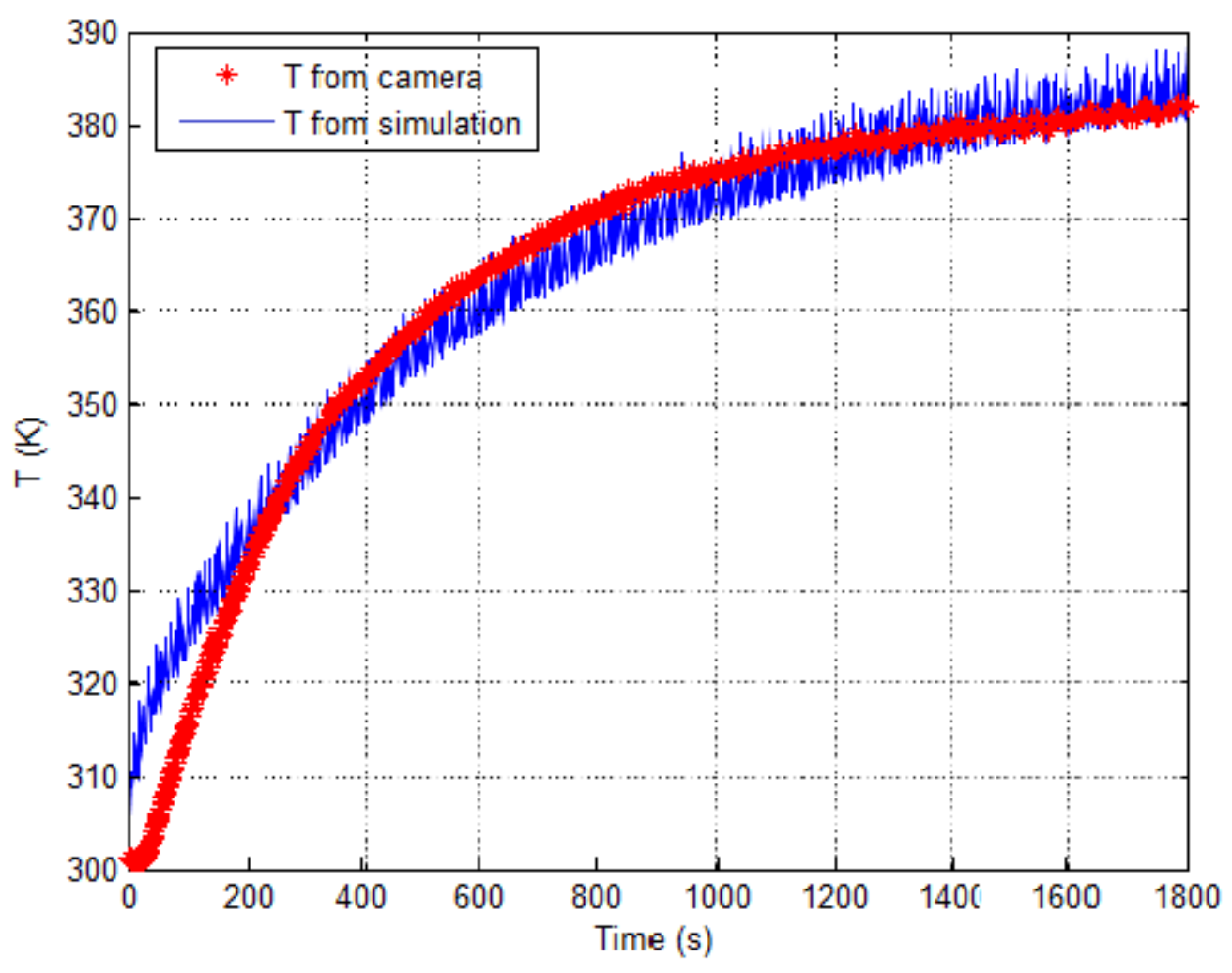

(c) 


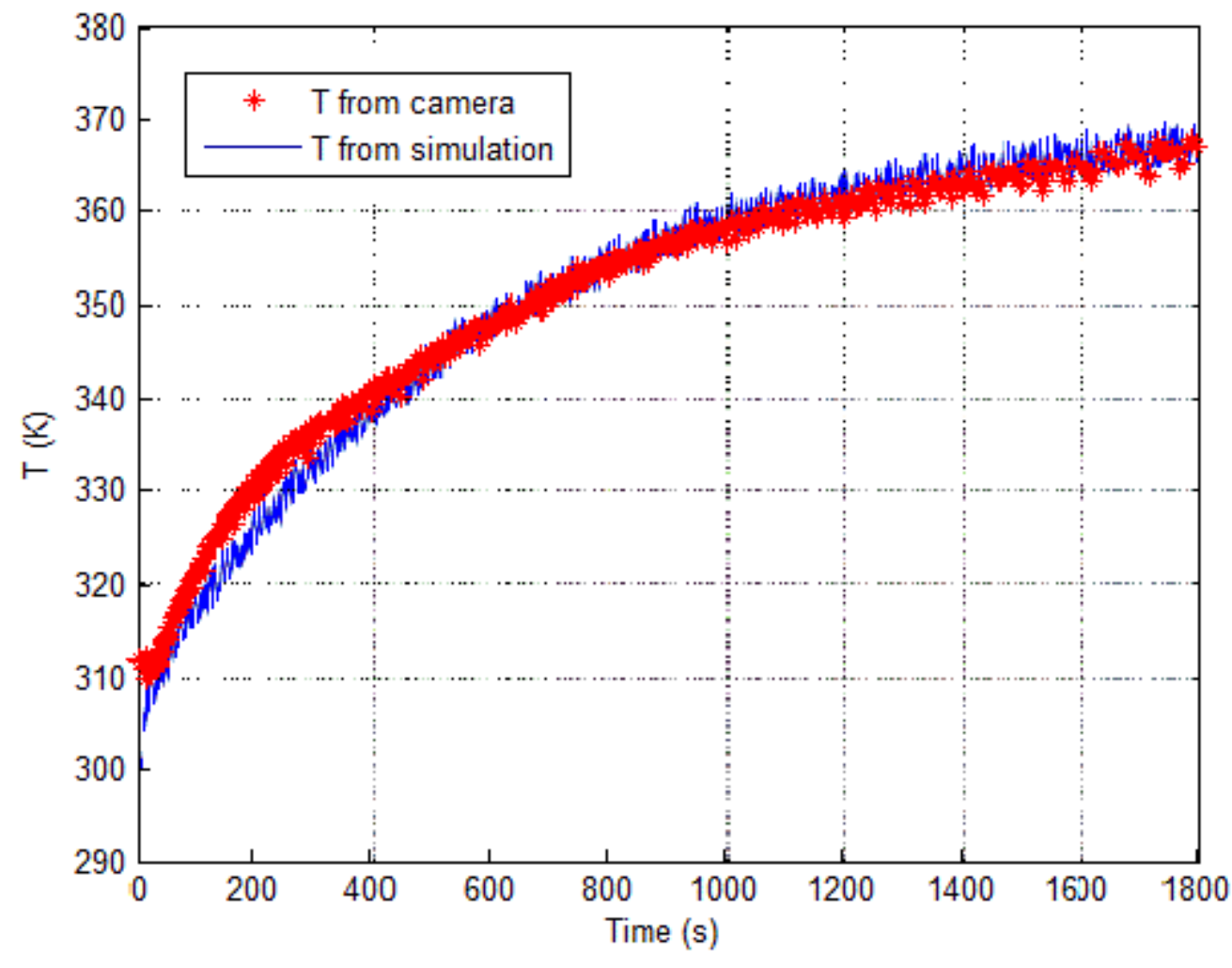

(d)

Figure 9. Evolution of the temperature on the different points of the outer surface: (a) position of the points; (b) evolution of the T on the bottom point; (c) evolution of the T on the center point; (d) evolution of the Ton the top point

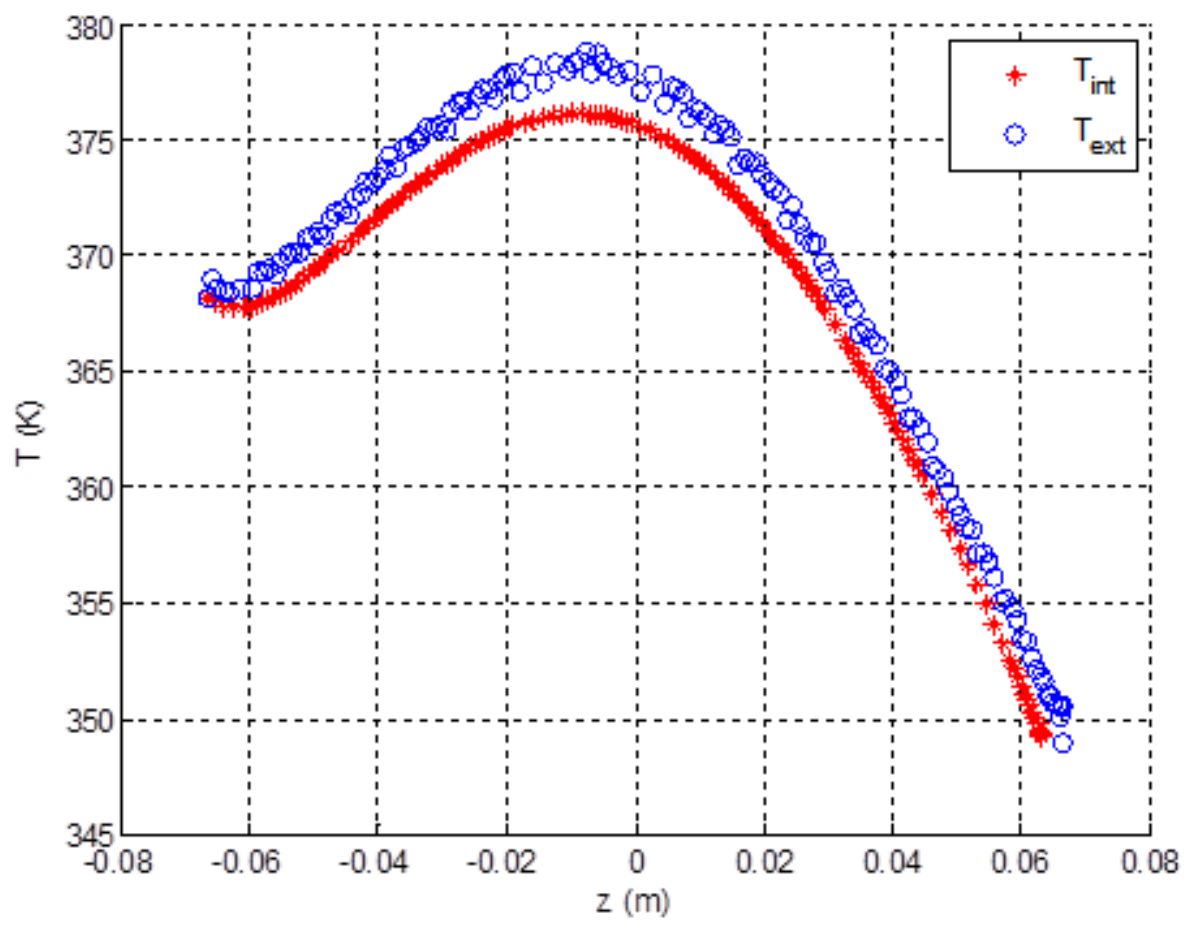

Figure 10. The distribution of temperature along the inside and outside surface of the preform at the quasi-steady state 


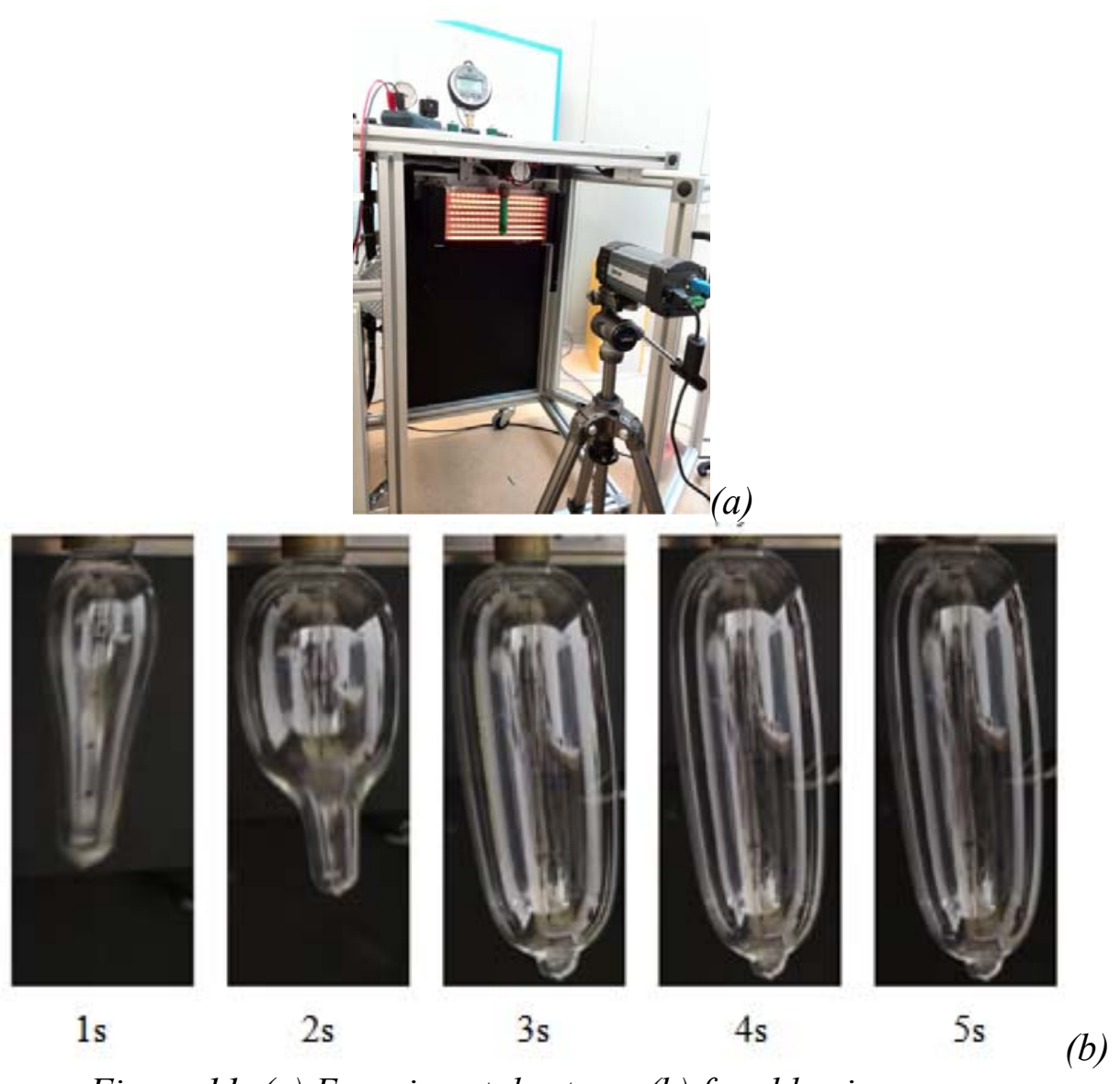

Figure 11. (a) Experimental set-up; (b) free blowing process 
Table (1).Thermal properties of PET

\begin{tabular}{|c|c|c|c|c|c|c|c|c|}
\hline \multirow[t]{2}{*}{ Parameter } & \multicolumn{4}{|c|}{$\begin{array}{c}\rho C_{p} \\
\left(\mathrm{~J} / \mathrm{m}^{3} . \mathrm{K}\right)\end{array}$} & \multirow[t]{2}{*}{$\begin{array}{c}k \\
(\mathrm{~W} / \mathrm{m} \cdot \mathrm{K})\end{array}$} & \multicolumn{2}{|c|}{$\begin{array}{c}h \\
\left(\mathrm{~W} / \mathrm{m}^{2} . \mathrm{K}\right)\end{array}$} & \multirow[t]{2}{*}{$\begin{array}{c}k_{\lambda} \\
\left(\mathrm{m}^{-1}\right)\end{array}$} \\
\hline & $\rho C_{p 1}$ & $T_{g}$ & $\Delta \rho C_{p}$ & $\alpha$ & & $h_{f}$ & $h_{r}$ & \\
\hline Value & $1.6810^{5}$ & 87 & $2.310^{6}$ & 0.1 & 0.26 & 12 & 13 & $3.10^{4}$ \\
\hline
\end{tabular}

Table (2).Estimated calculation time

\begin{tabular}{l|l|l|l|l}
\hline$N_{\phi}$ & 6 & 30 & 50 & 60 \\
\hline $\begin{array}{l}\text { Solved physical time } \\
\text { per day }\end{array}$ & $39 \mathrm{~s} /$ day & 11 s/day & 7 s/day & 6 s/day \\
\hline Calculation time & 20.5 days & 72 days & 114 days & 133 days \\
\hline
\end{tabular}

Table (3).Convection heat transfer coefficients $h$ from the presentnumerical simulation and the correlation Bejan (1995)

\begin{tabular}{l|c|c|c}
\hline & $\begin{array}{c}\text { Bottom region } \\
(\mathrm{y}=1 \mathrm{~mm})\end{array}$ & $\begin{array}{c}\text { Middle region } \\
(\mathrm{y}=62.5 \mathrm{~mm})\end{array}$ & $\begin{array}{c}\text { Top region } \\
(\mathrm{y}=125 \mathrm{~mm})\end{array}$ \\
\hline$T_{w}(\mathrm{~K})$ & 330 & 350 & 345 \\
\hline $\begin{array}{l}\text { numerical } h \text { value } \\
\text { interpolated from }\end{array}$ & 12 & 10 & 8 \\
Eq. $8\left(\mathrm{~W} / \mathrm{m}^{2} . \mathrm{K}\right)$ & & & \\
\hline $\begin{array}{l}h \text { correlated from } \\
\text { Eq. } 9\left(\mathrm{~W} / \mathrm{m}^{2} . \mathrm{K}\right)\end{array}$ & 20 & 9 & 7,7 \\
\hline
\end{tabular}

\section{References}

"ANSYS FLUENT Theory Guide", Ch. 5, heat transfer, ANSYS, Inc. ISO 9001:2008, (2011).

Bejan A., "Convection heat transfer", third edition, John Wiley \& Sons, Inc, (1995).

Bordival M., "Modélisation et optimisation numérique de l'étape de chauffage infrarouge pour la fabrication de bouteilles en PET par injection-soufflage", PhD thesis, Ecole Nationale Supérieure des Mines de Paris, (2009).

Champin C., "Modélisation 3D du chauffage par rayonnement infrarouge et de l'étirage soufflage de corps creux en P.E.T. ", PhD thesis, Ecole Nationale Supérieure des Mines de Paris, (2007).

Cosson B., Schmidt F., Le Maoult Y., Bordival M., "Infrared heating stage simulation of semi transparent media (PET) using ray tracing method", Int J Mater Form, 4; 1-10, (2011).

Erchiqui F., Hamani I., Charrette A., "Modélisation par éléments finis du chauffage infrarouge des membranes thermoplastiques semi-transparentes", International Journal of Thermal Sciences 48, p 73-84, (2009).

Huang H.X., Deng Y.H., Huang Y.F., "Temperature profiles within reheated preform in stretch blow molding", ANTEC'05 (Boston, Massachusetts), May (2005).

Lebaudy Ph., Saiter J.M., Grenet J., Vautier C., "Temperature distribution in poly(ethylene terephthalate) plate undergoing heat treatment", Diffusion influence and application, Polymer, Vol 36, Iss 6, p 1217-1221,(1995). 
Luo Y.M., Chevalier L., Utheza F., Monteiro E., "Numerical Simulation of the Thermodependant Visco-hyperelastic Behaviour of PET near the Glass Transition Temperature: prediction of the self heating during biaxail tension test", Polymer Eng. \& Science, Vol 53, Issue 12, 2683-2695 (2013).

Luo Y.M., Chevalier L., Utheza F., "Modelling the heat during the injection stretch blowing moulding: Infrared heating and blowing modeling", Proceedings of the ASME 2012 11th Biennial Conference On Engineering Systems Design And Analysis, Nantes, France, 2-4 July, (2012).

Luo Y.M., Chevalier L., Utheza F., Nicolas X., "Simplified Modelling of the Infrared Heating Involving the Air Convection Effect before the Injection Stretch Blowing Moulding of PET Preform", ESAFORM, Espoo, Finland, May (2014).

Menary G., "The Effect of Temperature, Strain Rate and Strain on the Induced Mechanical Properties of Biaxially Stretched PET", The 17th annual ESAFORM Conference on Material Forming, Erlangen, German, 14-16 March (2012).

Monteix S., "Modélisation du chauffage convecto-radiatif de préformes en P.E.T. pour la réalisation de corps creux". PhD thesis, Ecole Nationale Supérieure des Mines de Paris (2001).

Monteix S., Schmidt F., Le Maoult Y., "Experimental study and numerical simulation of preform or sheet exposed to infrared radiative heating", Journal of Materials Processing Technology 119 (1-3), p 90-97. (2001).

Salomeia Y.M., Menary G.H., Armstrong C.G., "Experimental Investigation of Stretch Blow Molding, Part 1: Instrumentation in an Industrial Environment", Advances in Polymer Technology. 32, S1, p. E771-E783, March (2013).

Schmidt F.M., Le Maoult Y., Monteix S., "Modelling of infrared heating of thermoplastic sheet used in thermoforming process", Journal of Materials Processing Technology, 143-144, p 225-231, (2003).

Venkateswaran G., Cameron M. R., Jabarin S. A., "Effects of Temperature Profiles Through Preform Thickness on the Properties of Reheat- Blown PET Containers", Advances in Polymer Technology, Vol 17, Issue 3, 237-249 (1998).

Yousefi A., DiRaddo R., Bendada A., "Simulation of the mobile preform reheat in injection stretch blow moulding process", Polymer Proceeding Society 17. Montreal, Canada. May 2124 (2001). 